\title{
Preparation and wear properties of high-vanadium alloy composite layer
}

\author{
Fangfang WANG ${ }^{1}$, Liujie XU ${ }^{1,2, *}$, Shizhong WEI ${ }^{3, *}$, Xi WANG ${ }^{2}$, Chong CHEN ${ }^{2}$, Yucheng ZHOU ${ }^{3}$ \\ ${ }^{1}$ School of Materials Science and Engineering, Henan University of Science and Technology, Luoyang 471003, China \\ ${ }^{2}$ National Joint Engineering Research Center for Abrasion Control and Molding of Metal Materials, Henan University of \\ Science and Technology, Luoyang 471003, China \\ ${ }^{3}$ Engineering Research Center of Tribology and Materials Protection, Ministry of Education, Henan University of Science and \\ Technology, Luoyang 471003, China
}

Received: 13 January 2020 / Revised: 18 July 2020 / Accepted: 30 March 2021

(C) The author(s) 2021.

\begin{abstract}
A high-vanadium alloy composite layer was prepared on the surface of a carbon steel using cast composite technology, and the wear properties of the composite layer were investigated. The results showed that the microstructure of the composite layer was composed of primary vanadium carbides (VC), flake martensite, residual austenite, and fine VC. The hardness of the cast alloy layer was 63 HRC. The abrasive wear resistance and impact wear resistance were increased by $60 \%$ and $26 \%$, respectively, compared with those of high-chromium cast iron. The excellent wear resistance of the cast alloy layer is attributed to the high-hardness primary vanadium carbide and the large number of fine secondary vanadium carbides precipitated out of the cast alloy layer.
\end{abstract}

Keywords: high-vanadium alloy layer; wear resistance; vanadium carbide; solidification process

\section{Introduction}

Wear failure is one of the three main forms of failure in mechanical equipment and parts, namely, fracture, corrosion, and wear. Increasing the carbon content to form carbide is the main method to improve the wear resistance of steel materials in early research. The most common is cemented carbides such as tungsten, molybdenum, titanium, and chromium in the form of reinforced particles [1-6].

However, these materials have high brittleness, poor toughness, and poor comprehensive performance owing to their high alloy content, which requires frequent replacement and special heat treatment processes and consumes a lot of manpower and material resources. In addition, the price of these metals is high, resulting in increased production costs for large-scale use, which is not conducive for long-term development. Vanadium in steel not only refines the structure and grain size of the steel, increases the coarsening temperature of the grain, but also forms an MC-type vanadium carbide hard phase in the steel, improving the microhardness, toughness, and comprehensive properties of the material [7-12]. Thus, it is more in line with the economic benefits.

Material wear is mainly surface wear, that is, the process of surface deformation and fracture, such as the lining plate of the cone crusher. Surface composite technologies have been developed in recent years to improve the surface wear resistance of materials, such as fabricated laser cladding, high-energy electron beam irradiated plasma jet cladding, and plasma transfer arc [13-22]. However,

* Corresponding authors: Liujie XU, E-mail: wmxlj@126.com; Shizhong WEI, E-mail: hnwsz@126.com 
the surface wear-resistant layer fabricated by these methods is usually no more than $2 \mathrm{~mm}$ in thickness, which is relatively thin and easily falls off. Thus, this effect was not as expected. The casting infiltration method is a surface-strengthening technology that combines casting and metallurgical strengthening technologies. Under the action of a high-temperature liquid metal, the active atoms released by the decomposition of infiltrating agent elements diffuse into the base metal, and the target elements in the alloy powder infiltrate into the base metal. Compared with non-casting surface strengthening technology, the casting infiltration method has the advantages of a short production cycle, no deformation, and low cost of thick surface treatment parts [23, 24], and is an economical and effective surface strengthening method. Thus, this method has been used in the surface casting infiltration process of some parts with easily worn surfaces, such as the liner plate of the cone crusher.

Previously, casting infiltration technology was researched in depth [25-30]. Xu et al. [31] found that the composite layer formed by adding $20 \mathrm{vol} \%$ WC into the casting infiltrator has the best wearresistant performance and is 0.2-2.3 times higher than the boronizing layer composed of $\mathrm{Fe}_{2} \mathrm{~B}$, and the wear resistance of the rotary liner made of cement shotcrete is 0.8 times that of nodular cast iron. Uskov et al. [32] prepared a permeable layer with hard particles on the surface of ferrocarbon alloy castings and found that the wear resistance of the permeable layer with $\mathrm{SiC}$ or $\mathrm{Cr}_{7} \mathrm{C}_{3}$ was approximately three times that of the original material. Ye et al. [33] studied VCp/Fe surface composites prepared by in situ casting and infiltration, and found that the microhardness of the composite area was five times that of the iron matrix, and the wear resistance of the $\mathrm{VCp} / \mathrm{Fe}$ surface composites was excellent.

In this study, a high-vanadium high-wear-resistant alloy layer was developed using surface casting composite technology. The microstructure, solidification process, and wear properties of the casting alloy layer were studied. The comprehensive properties were tested to ensure that they met the requirements of the conical liner under severe working conditions.

\section{Experimental methods}

\subsection{Experimental materials}

The chemical composition of the high-vanadium alloy composite layer and parent metal was designed based on a previous study. High-vanadium high-speed steel was selected as the casting alloy layer [34]. Its raw materials include ferrovanadium powder (V: $55.54 \mathrm{wt} \%)$, ferrochrome powder (Cr: $62 \mathrm{wt} \%)$, ferromolybdenum powder (Mo: $58.5 \mathrm{wt} \%$ ), ferrosilicon powder (Si: $77.79 \mathrm{wt} \%)$, ferromanganese powder (Mn: $78.5 \mathrm{wt} \%$ ), high-carbon iron powder (C: $8 \mathrm{wt} \%$ ). A $200 \mathrm{~g}$ powder of 200-300 mesh was prepared based on the proportions shown in Table 1 . We chose medium carbon steel ZG310-570 (GB/T11352-2009) as the base material and referred to high-chromium cast iron BTMCr20 (GB/T8263-2010) with $20 \mathrm{wt} \%$ chromium content as the contrast material.

\subsection{Preparation of samples}

An ordinary sand mold casting process was adopted, and medium carbon steel ZG310-570 was used as the base material. A high-vanadium high-wear-resisting alloy layer was obtained on the surface of ZG310570 steel by cast composite processing. The formation process of the casting infiltration layer is illustrated in Fig. 1. The alloy powders were mixed in a ball mill for 10 hours to ensure that different alloy powders were evenly mixed. During this period, the adhesive polyvinyl butyral (PVB) resin with a proportion of alcohol of 4:96 was added. The ratio of the mixed solution to the alloy powder was 1:10. The mixed alloy powder was mushy, coated in a specific position of the sand mold, and ignited to dry it. Medium carbon steel ZG310-570 was melted in a medium-frequency furnace at a casting temperature of $1,680{ }^{\circ} \mathrm{C}$. The temperature of the liquid steel when it contacted the mixed alloy powder, which was coated on the sand mold, was approximately $1,500{ }^{\circ} \mathrm{C}$ based on the test results by placing a thermocouple on the surface of the coated alloy powder. The high-temperature metal liquid was poured to fill the powder pores, and the molten metal melted the powder grains to form the desired percolation layer on the surface of the casting and 


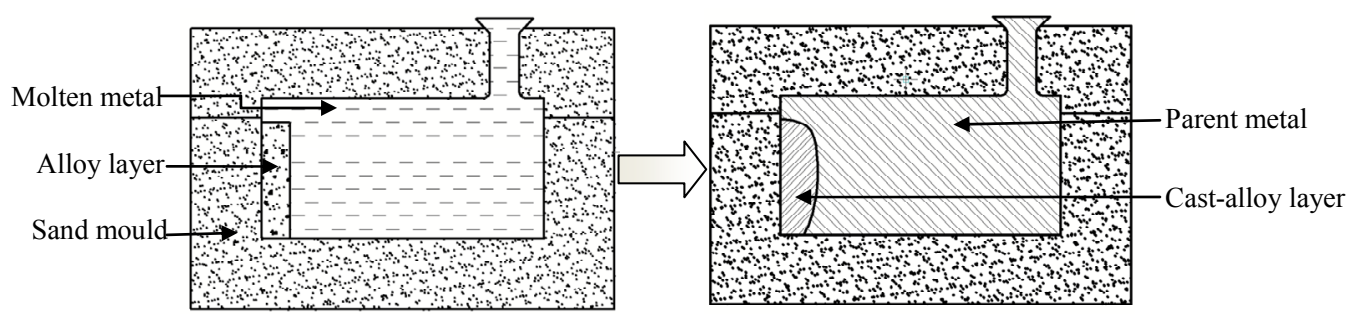

Fig. 1 The forming process of cast alloy layer.

Table 1 Original design composition of cast-alloy layer (wt $\%)$.

\begin{tabular}{cccccccc}
\hline Material & $\mathrm{V}$ & $\mathrm{C}$ & $\mathrm{Cr}$ & $\mathrm{Mo}$ & $\mathrm{Si}$ & $\mathrm{Mn}$ & $\mathrm{Fe}$ \\
\hline Sample & 20 & 4.44 & 5.5 & 2 & 0.6 & 0.6 & Balance \\
\hline
\end{tabular}

therefore formed a cast composite layer with the required performance effect on the casting surface. The cast sample was heat-treated in a box electric resistance furnace. The austenitizing temperature of the sample is $1,000{ }^{\circ} \mathrm{C}$, holding time of two hours, and then air cooling [35].

\subsection{Microstructure analysis and worn surface observation}

The microstructure and worn surface of the casting composite layer were observed using a scanning electron microscope (SEM, VEGA3-TESCAN-SBH), and an energy spectrometer (EDS) was used to analyze the distribution of the carbides in the casting composite layer and the excessive elements in the casting composite layer interface. The phase structures of the carbides and matrix in the casting composite layer were analyzed using a D8 Advanced X-ray diffractometer (XRD) and a Hitachi H-800 transmission electron microscope (TEM). The residual austenite and martensite contents in the cast alloy layer were determined by XRD analysis.

\subsection{Performance test}

\subsubsection{Mechanical property testing}

The Rockwell hardness of the specimens was measured using an HR-150A Rockwell hardness tester. Five points were measured for each sample, with the last value being the average of the five values. The microhardness was tested using a micro-hardness tester (HVS-1000A) with a load of $200 \mathrm{~g}$ and a dwell time of $20 \mathrm{~s}$. The microhardness at a certain distance from the cast alloy layer to the base material was measured, and the measured data were plotted to observe the changes.

\subsubsection{Abrasive wear performance test}

The wear test was conducted on a pin-on-disk wear testing machine (type ML10) using 160-grit waterproof-abrasive sandpaper (Fig. 2). The samples were pins, and the specimen size was $\phi 6 \times 20 \mathrm{~mm}$. The disk of the testing machine was rotated at a speed of $60 \mathrm{rpm}$ when the pin moved at a speed of $6 \mathrm{~mm} / \mathrm{s}$ from the center of the disk to the brim of $100 \mathrm{~mm}$ at a load of $200 \mathrm{~N}$. Before starting the experiment, each sample was grounded for $3 \mathrm{~min}$, and the surface of the sample was polished as smoothly as possible. The sandpaper was replaced upon replacement of the sample, maintaining the consistency of the experimental conditions. Each sample was reciprocated by 20 sets of movements each time, and the wear weight loss was then measured. To avoid the contingency of the test results, three sets of parallel experiments were conducted for each sample, and the weight loss was the average result. The wear resistance was specified as $\beta$ with $\beta=W^{-1}$. The weight loss of the sample was measured using a TG328B analytical balance, which ranged from 0 to $200 \mathrm{~g}$ and had a relative accuracy of $0.1 \mathrm{mg}$.
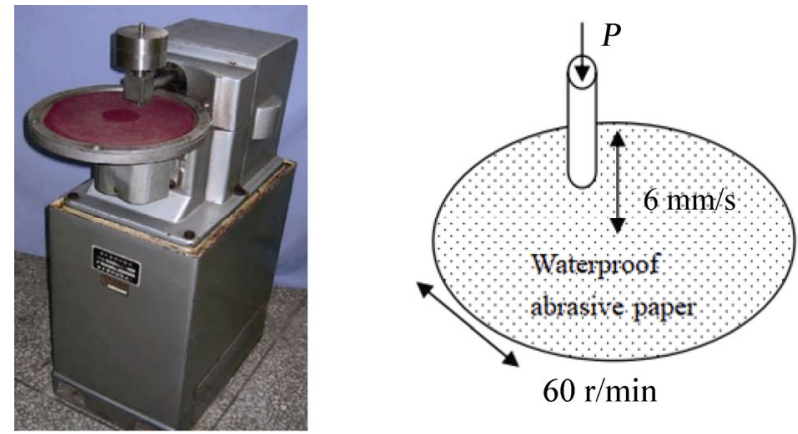

Fig. 2 The photo and principle of abrasive wear testing machine. 
The path of the sample in the experiment was a spiral line. Based on the calculation formula of the spiral line, the total wear distance of the sample can be expressed as follows:

$$
S=\frac{\pi N\left(r_{1}^{2}-r_{2}^{2}\right)}{r_{1}-r_{2}}
$$

where $S$ is the wear distance, $N$ is the total wear turn, and $r$ is the friction radius.

\subsubsection{Impact wear performance test}

The test was performed on an MLD-10 impact wear test machine, as shown in Fig. 3. A specimen size of $10 \mathrm{~mm} \times 10 \mathrm{~mm} \times 30 \mathrm{~mm}$ was prepared by linear cutting, and high-chromium cast iron BTMCr20 was used as the contrast sample. The weight of the hammerhead of the impact wear testing machine was $10 \mathrm{~kg}$, the impact energy was $3 \mathrm{~J}$, and was controlled by the distance between the impact surface of the sample and the impact axis, the speed of the wear impact shaft was $200 \mathrm{rpm}$, and the impact frequency was 200 times per minute. Quartz sand was used as the abrasive with a hardness of approximately 1,120 $\mathrm{HV}$, an average particle size of $0.60-0.94 \mathrm{~mm}$, and a flow rate of $48 \mathrm{~kg} / \mathrm{h}$. Each group was tested for 1 hour and weighed every $15 \mathrm{~min}$. Three parallel experiments were conducted in each group to ensure the reliability of the test results and the average value was obtained.

\section{Experimental results}

\subsection{Chemical compositions}

The actual chemical compositions of the casting composite layers of the samples are shown in Table 2.

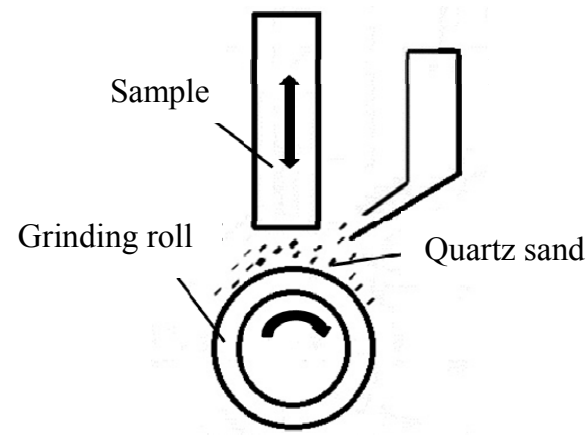

Fig. 3 Principle of impact wear testing machine.
Table 2 Chemical composition (wt\%).

\begin{tabular}{lcccccccc}
\hline \multicolumn{1}{c}{ Element } & $\mathrm{V}$ & $\mathrm{C}$ & $\mathrm{Cr}$ & $\mathrm{Mo}$ & $\mathrm{Si}$ & $\mathrm{Mn}$ & $\mathrm{Fe}$ & $\mathrm{P} / \mathrm{S}$ \\
\hline $\begin{array}{l}\text { High vanadium } \\
\text { alloy layer }\end{array}$ & 6.6 & 2.2 & 4.4 & 1.2 & 0.6 & 0.6 & Balance $\leqslant 0.07$ \\
$\quad$ BTMCr20 & - & 2.8 & 20.2 & 2 & 0.7 & 1.02 & Balance $\leqslant 0.07$ \\
\hline
\end{tabular}

\subsection{Microstructure}

\subsubsection{Microstructure of the interface}

Figure 4 shows the interface between the casting alloy layer and parent metal. There was no obvious porosity inclusion or other serious casting defects at the interface (Fig. 4(a)). Figure 4(b) indicates that the interface includes the parent metal, transition layer, and casting alloy layer. The thickness of the transition layer was 30-50 $\mu \mathrm{m}$, and the thickness of the alloy layer was approximately $5 \mathrm{~mm}$. Compared with other surface composite layers prepared by non-casting methods, the cast surface composite layer was thicker.

Line scan analysis of the casting composite layer was conducted using an electronic probe instrument (as shown in Fig. 5). The distributions of $\mathrm{V}$ and $\mathrm{C}$ in the casting composite layer were mainly observed. As shown in Fig. 5, a large number of $\mathrm{V}$ and $C$ exist in the casting alloy layer and the contents of $\mathrm{V}$ and $\mathrm{C}$ gradually decrease from the casting alloy layer to the base material, which indicates that $\mathrm{V}$ and $\mathrm{C}$ have certain diffusion and infiltration in these two fields. The distribution of vanadium and carbon in the cast alloy layer was not uniform, which was caused by the formation of vanadium carbide in the cast alloy layer. The matrix structure of the parent metal ZG310-570 steel was lamellar pearlite, whereas that of the casting alloy layer was plate martensite.

\subsubsection{Microstructure of the alloy casting composite layer}

Figure 6 shows the XRD analysis results of the high-vanadium alloy casting layer before and after the heat treatment. From the figure, the as-cast alloy layer is mainly composed of martensite and MC carbides. Primary carbides are mainly distributed in grain boundaries because austenite grows gradually during the solidification process, 

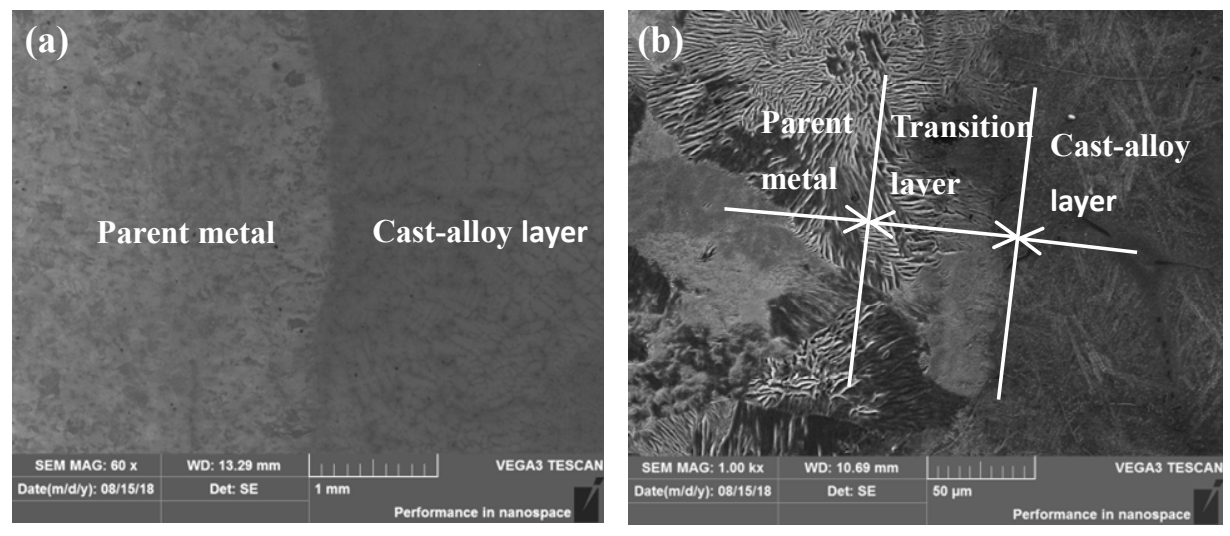

Fig. 4 Cast composite sample matrix and the combination of cast alloy layer.

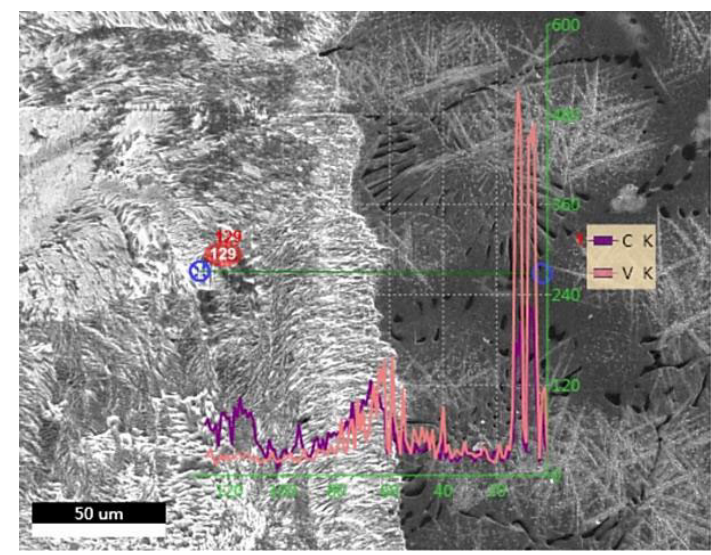

Fig. 5 Line scan of the interface between the cast alloy layer and the matrix.

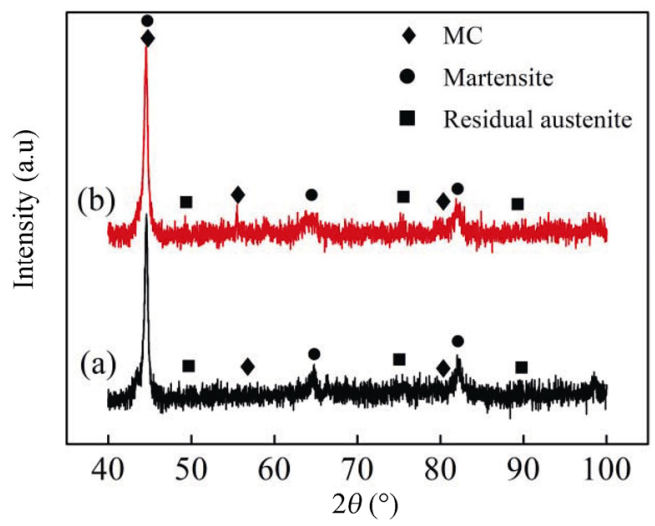

Fig. 6 XRD diffraction pattern of cast alloy layer: (a) as-cast, (b) heat treatment state.

forcing new vanadium carbides to return to the grain boundary and concentrate at the grain boundary edge. In addition, the vanadium carbide particles and steel matrix exhibited good wettability. A small amount of carbide particles was adsorbed by the parent material matrix during the solidification process and eventually appeared at the matrix grain boundary.

The EDS analysis results for areas $\mathrm{A}$ and $\mathrm{B}$ are shown in Fig. 7. As shown in Fig. 7(d), area A is mainly composed of $\mathrm{C}$ and $\mathrm{V}$ elements, and the content of $\mathrm{V}$ is significantly higher than that in area $\mathrm{B}$; therefore, area $\mathrm{A}$ is dominated by VC-type vanadium carbide. Region B contains a large amount of Fe in addition to $\mathrm{C}$ and $\mathrm{V}$ elements, which indicates that this region is mainly composed of Fe matrices, as well as some vanadium carbides. A careful observation of Figs. 3-5 shows that there are a certain number of nanoparticles in the matrix grains, with particle sizes ranging from tens of nanometers to hundreds of nanometers. Based on the EDS analysis of area B in Fig. 7(e), a certain amount of vanadium was present in the carbides. Therefore, it can be speculated that it may be vanadium carbide.

In the process of solidification and eutectic reaction, the austenite and vanadium carbide grow into reverse-banded carbides in different directions, which can result in a high pinning effect of the hard phase, eventually resulting in excellent wear resistance of the casting material of the cast composite layer.

Figure 8 shows a TEM image of the sample after heat treatment, which shows that the fine carbide has a face-centered cubic structure, and the crystal band axis of VC is [022]. Previous research has shown that in the chemical composition formula of vanadium carbide, the coefficient of carbon is always less than 1 decimal [36]. $\theta$

Figure 9 shows an SEM image of the sample after 

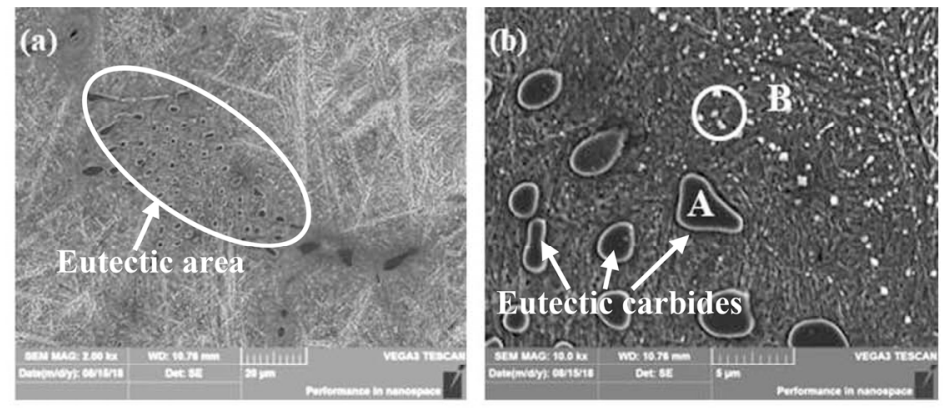
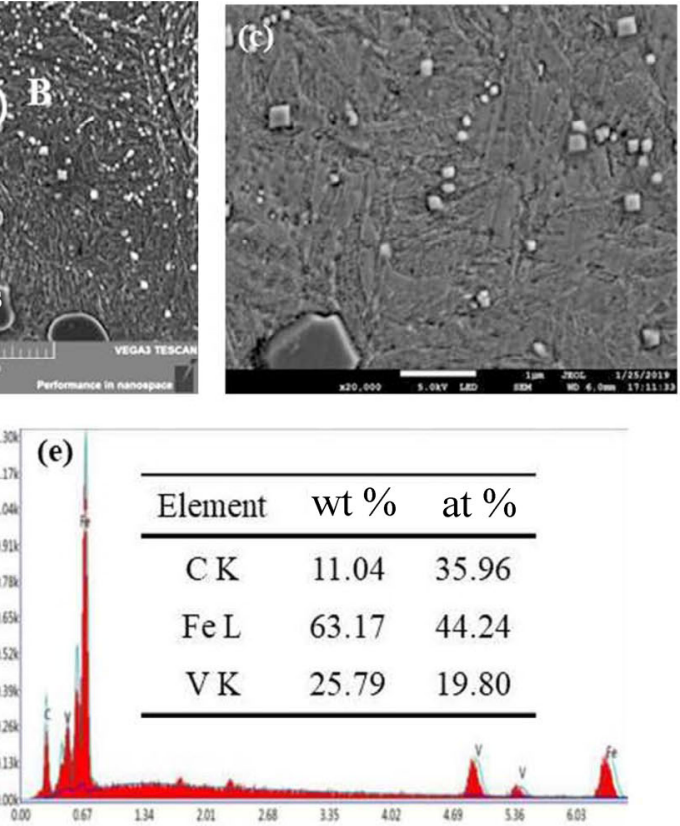

Fig. 7 SEM diagrams of the cast alloy layer for as-cast are (a), (b) and (c), EDS diagrams of areas A and B respectively are (d) and (e).
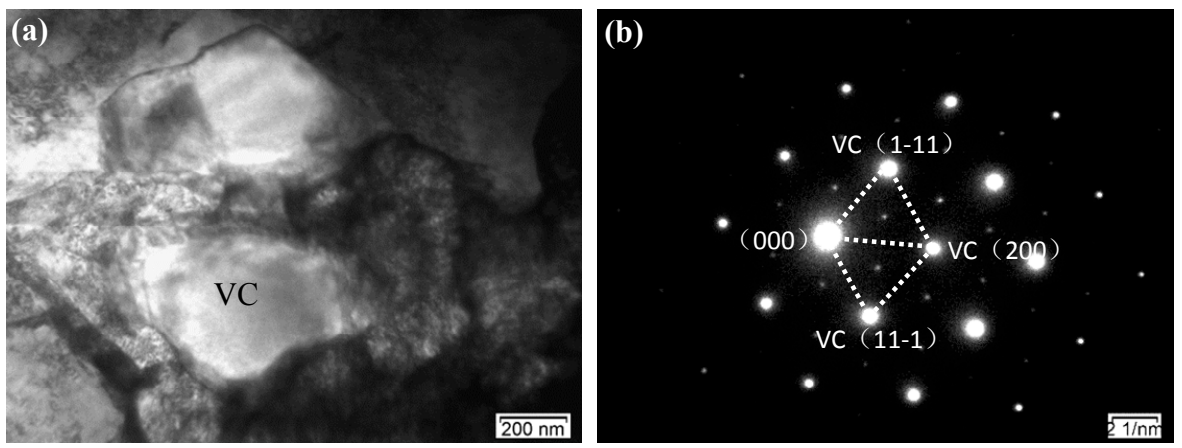

Fig. 8 TEM analysis of VC: (a) TEM image, (b) calibration of electron diffraction pattern.
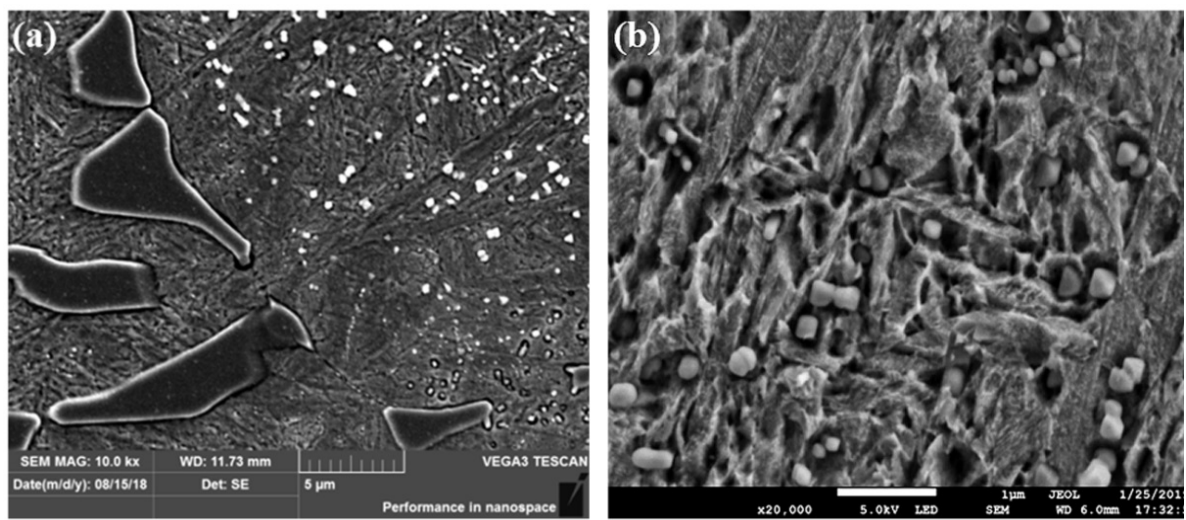

Fig. 9 SEM image of cast alloy layer after heat treatment: (a) $10.0 \mathrm{kx}$, (b) $20.0 \mathrm{kx}$.

heat treatment. The contents of primary VC, secondary reinforcing particles, and residual austenite before and after heat treatment are shown in Table 3. Based on the calculation by Image J software, the total amount of carbide was approximately $21 \mathrm{vol} \%$. The number of secondary reinforcing particles in the 
Table 3 The volume content of each phase in the microstructure before and after heat treatment (vol\%).

\begin{tabular}{ccccc}
\hline Sample & $\begin{array}{c}\text { Primary } \\
\text { carbide }\end{array}$ & $\begin{array}{c}\text { Secondary } \\
\text { reinforcing } \\
\text { particles }\end{array}$ & $\begin{array}{c}\text { Residual } \\
\text { austenite }\end{array}$ & Martensite \\
\hline As-cast & 18.02 & 2.93 & 12.77 & 66.28 \\
Heat treatment state & 15.73 & 5.70 & 9.18 & 69.39 \\
\hline
\end{tabular}

grain and grain boundaries increased significantly, which was $50 \%$ higher than that in the as-cast state. The shape and distribution were uniform and dense. However, after heat treatment, the martensite content in the microstructure decreased slightly, the residual austenite increased slightly, and the hardening improved.

\subsection{Hardness}

The Rockwell hardness of the high-vanadium casting composite layer was $54 \mathrm{HRC}$ in the casting state and $63 \mathrm{HRC}$ in the heat treatment state. This is owing to secondary hardening during the heat treatment process. The secondary reinforced particles in the matrix increased significantly after the heat treatment, resulting in an obvious increase in hardness. The hardness of BTMCr20 was 57 HRC.

Figure 10 shows the microhardness at different positions from the surface of the casting composite layer to the parent metal, with a maximum hardness of $3-4 \mathrm{~mm}$. Based on the analysis, the surface of the casting composite layer is in contact with the sand mold, and the heat dissipation is fast, the fusion quality is relatively poor in the interior, the structure is relatively loose, and there are casting defects such as pore residue; thus, the microhardness is relatively low at the infant stage. With the deepening of the solidification process, the defects in the casting decreased, and the microhardness increased significantly. The microhardness reached its peak in the middle of the alloyed layer. When the casting alloyed layer solidifies to the middle, the microhardness is the highest because the microstructure crystallizes many times and the formation of hard phase concentration is higher. Under the action of heat, the elements in the transition zone diffuse into the matrix, resulting in a decrease in the concentration of the elements in the transition layer and a relative decrease in the

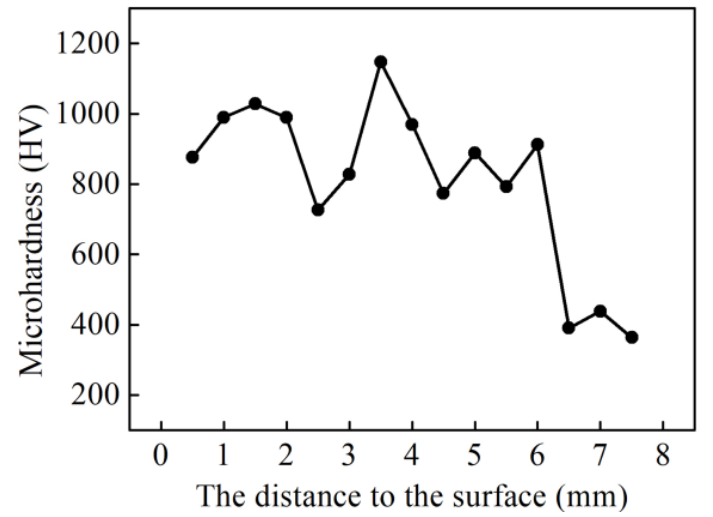

Fig. 10 Microhardness distribution of cast alloy layer.

hardpoints or hard phases formed, resulting in a significant decrease of the hardness in the transition zone. Moreover, from the variation trend, the individual beats fluctuate greatly, which may be caused by the hardness of the different regional phases in the casting composite layer.

\subsection{Wear performance}

\subsubsection{Abrasive wear performance}

Table 4 shows the wear properties of the samples after the heat treatment. It can be seen from Table 4 that the wear amount of the casting composite layer was small. The wear resistance of the high-vanadium alloy layer is 1.6 times that of the contrast material (BTMCr20), and the wear resistance is better.

Figure 11 shows the abrasion morphologies of the casting composite layer and BTMCr20. The grooves formed by the abrasive wear in the cast composite layer were relatively shallow, whereas the surface grooves of sample BTMCr20 were relatively deep. This is because many blocks and ball VCs can effectively resist abrasive scratches.

As shown in Fig. 12, after the abrasive wear experiment, the furrow formed on the surface of BTMCr20 was deep, and the carbides under the worn surface produced serious cracks and fragmentation. In contrast, the furrow formed on the surface of the cast composite layer was shallow, and there was no carbide shedding or microcrack formation. Therefore, the abrasion resistance of the cast alloy layer of the sample is much better than that of BTMCr20. 

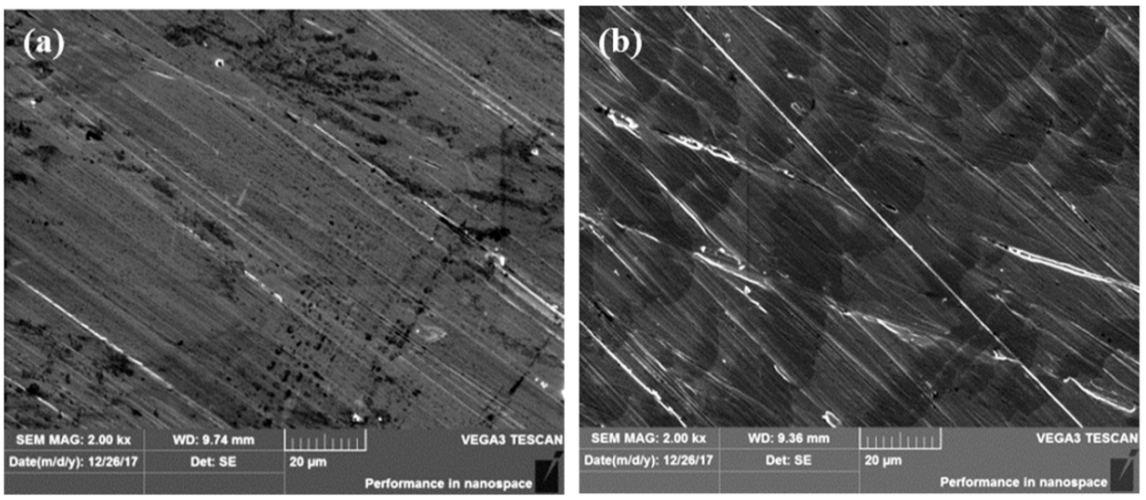

Fig. 11 The wear morphology of the sample cast alloy layer and BTMCr20: (a) high vanadium alloy layer, (b) BTMCr20.
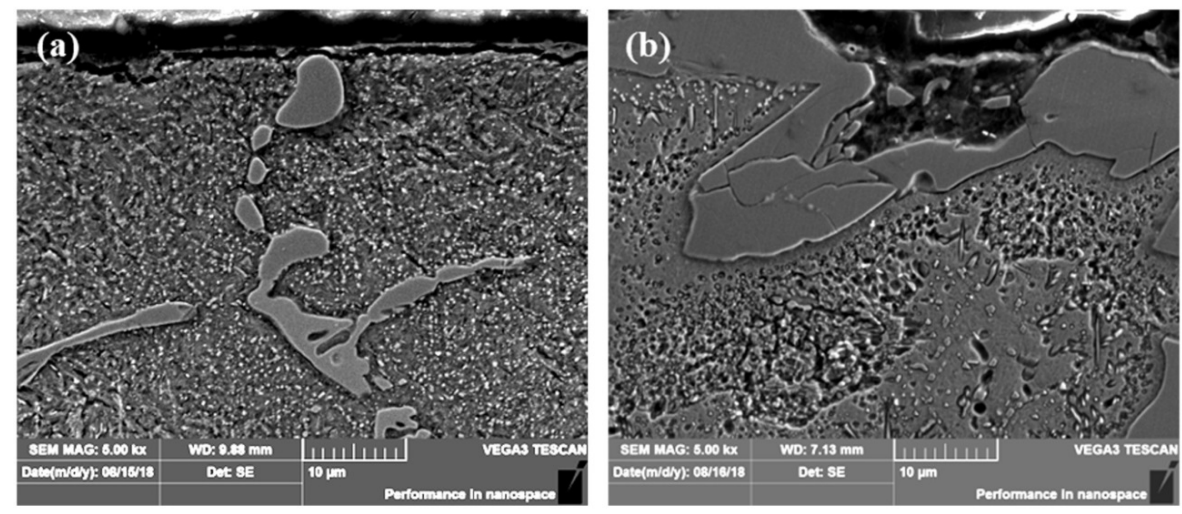

Fig. 12 SEM cross section after abrasive wear test: (a) high vanadium alloy layer, (b) BTMCr20.

Table 4 Abrasive wear properties of materials.

\begin{tabular}{ccc}
\hline Sample & $\begin{array}{c}\text { Wear weight } \\
\text { loss }(\mathrm{mg})\end{array}$ & $\begin{array}{c}\text { Relative wear } \\
\text { resistance }\end{array}$ \\
\hline $\begin{array}{c}\text { High vanadium alloy layer } \\
\text { BTMCr20 }\end{array}$ & 24.6 & 1.6 \\
\hline
\end{tabular}

\subsubsection{Impact wear performance}

Figure 13 shows the impact wear properties of the casting composite layer of the sample. As shown in Fig. 13(a), the wear weight loss in the first period of impact was significantly higher than that in the later period. Compared with the high-chromium cast iron BTMCr20, the cast composite layer exhibited the least wear loss and excellent wear resistance. As can be seen from Fig. 13(b) and Table 5, the impact wear resistance of the cast alloy layer is 1.26 times that of BTMCr20. Using XRD, the residual austenite content in the samples after impact wear was calculated. It was found that the residual austenite content in the samples was $18 \mathrm{vol} \%$, which resulted from impact-induced martensite transformation.

Figure 14 shows the impact wear morphology of the casting composite layer and the high-chromium cast iron BTMCr20 after heat treatment. The wear surfaces mainly include chisel pits and cutting furrows. The impact wear surface morphology of the high-vanadium casting composite layer is mainly spalling pits, whereas the wear surface morphology of high-chromium cast iron includes spalling pits and grooves, and some cracks. It can be seen from the figure that the wear degree of the high-chromium cast iron BTMCr20 is more serious, thus the wear resistance is poor.

Figure 15 shows the cross-section of the worn surface after the impact wear test. From the figure, the impact pit of the casting composite layer is shallow and there is no obvious groove. After the impact, the carbides in the subsurface do not produce fractures or sloughing. The impact surface of BTMCr20 has an obviously deep and wide furrow, 

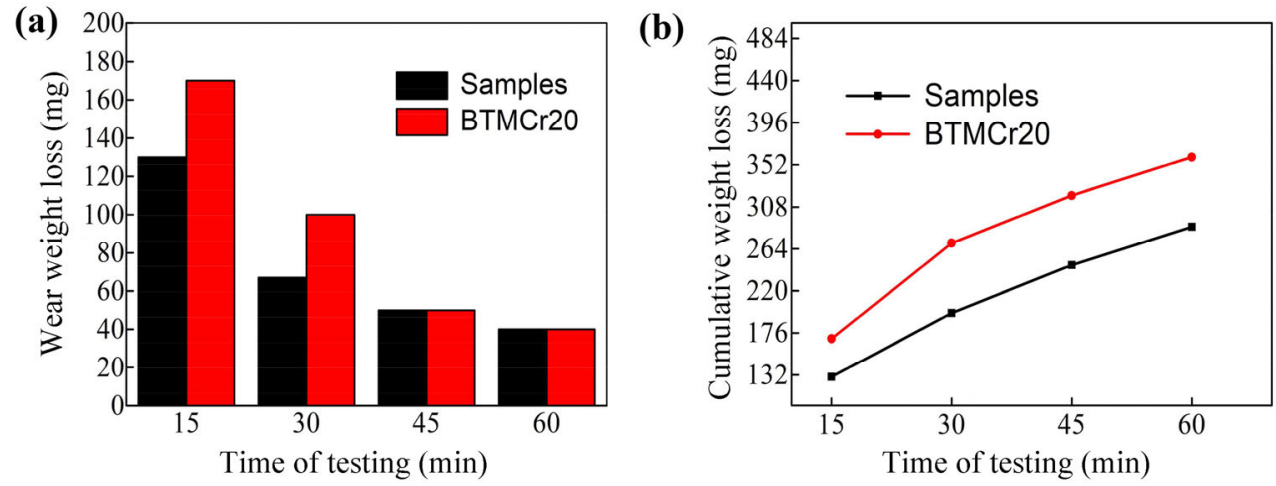

Fig. 13 Impact wear weight loss of the casting composite layer and contrast material BTMCr20.
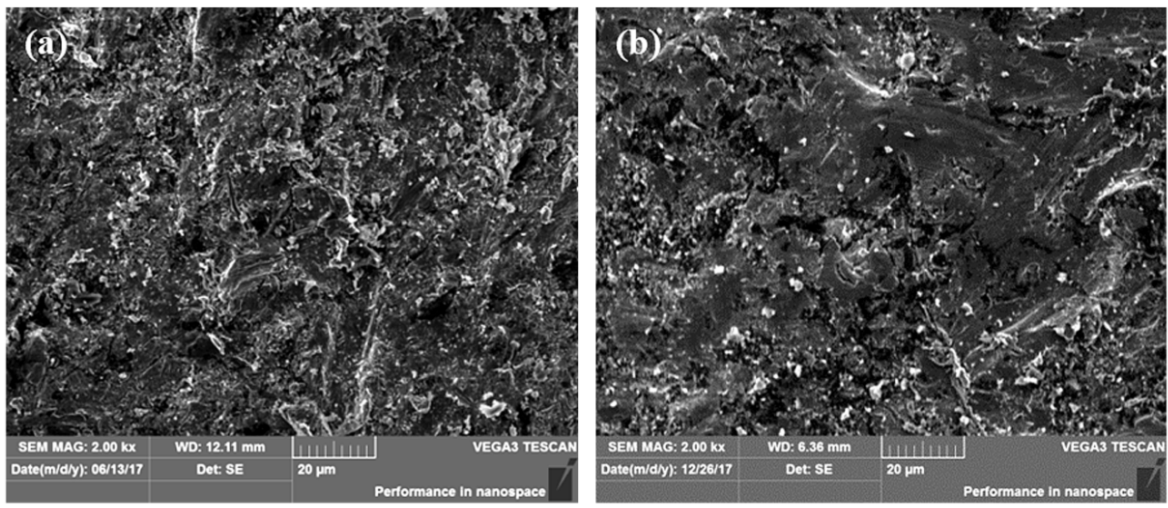

Fig. 14 The impact wear morphology: (a) high vanadium alloy layer, (b) BTMCr20.
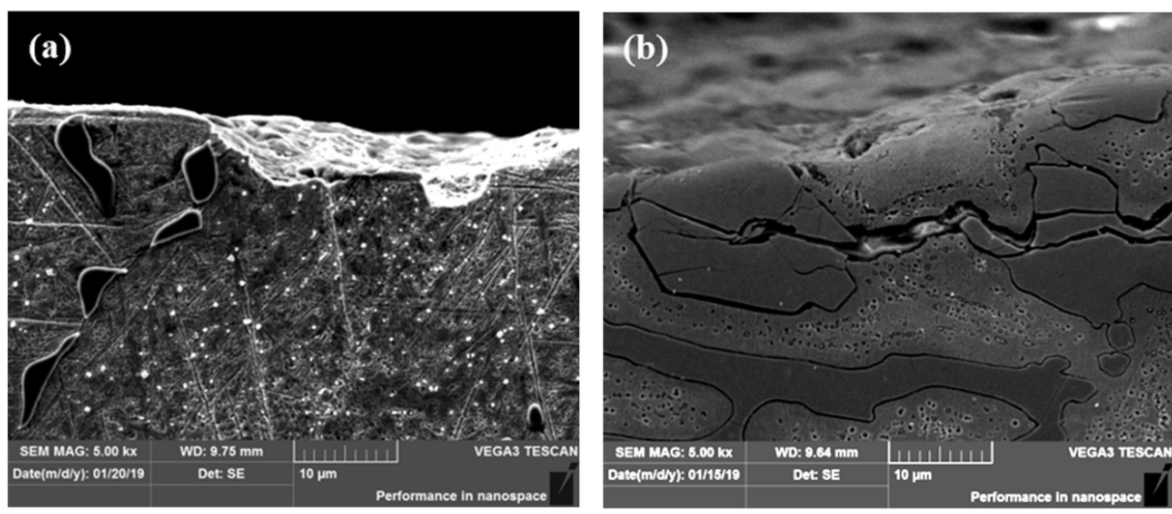

Fig. 15 SEM cross section after impact wear test: (a) high vanadium alloy layer, (b) BTMCr20.

Table 5 Impact wear properties of materials.

\begin{tabular}{ccc}
\hline Sample & $\begin{array}{c}\text { Wear weight } \\
\text { loss }(\mathrm{mg})\end{array}$ & $\begin{array}{c}\text { Relative wear } \\
\text { resistance }\end{array}$ \\
\hline High vanadium alloy layer & 287 & 1.26 \\
BTMCr20 & 360 & 1 \\
\hline
\end{tabular}

the subsurface has a serious fracture phenomenon, and the fracture and microcrack phenomenon in the carbide is more serious. Under the combined action of $\mathrm{VC}$ and the fine secondary carbide dispersed in the matrix, the casting alloyed layer not only has high hardness but also good toughness. Therefore, it has good comprehensive performance and cannot easily generate microcracks. However, the cracks in high-chromium cast iron mainly originate from the inside of $\mathrm{M}_{7} \mathrm{C}_{3}$ carbides, which are mainly caused by the plugging of dislocations and the formation of dense cracks around $\mathrm{M}_{7} \mathrm{C}_{3}$ carbides. These dense cracks spreaded over a short distance and formed 
large cracks through the interconnection of the main cracks, resulting in the rapid failure of highchromium cast iron. Therefore, the wear resistance of the high-vanadium casting composite layer was excellent.

\section{Discussion}

\subsection{Solidification process of casting composite layer}

In 1994, Ogi described the liquid phase projection diagram of the Fe-5Cr-V-C alloy during the solidification process (as shown in Fig. 16) [37]. The Fe-5Cr-V-C alloy studied in the projection diagram is consistent with the composition of the alloy in this test and can be used as a theoretical reference for analyzing the crystallization process of the alloy in this test.

Based on the solidification theory, the liquid phase line always moves in the direction of temperature reduction [37]. This diagram mainly describes the phase transformation during the solidification process of high carbon steel, including the chemical components of the high-speed steel used in this experiment, which can be used to explain the solidification process. When the high-speed steel solidifies in the sand mold, owing to the limited heat capability and low thermal conductivity, the heat diffusion rate is low, and the degree of supercooling is low. As the temperature decreased, the primary $\gamma$ phase first precipitated from the liquid phase between points 1 and 2 , and the $\mathrm{L} \rightarrow$

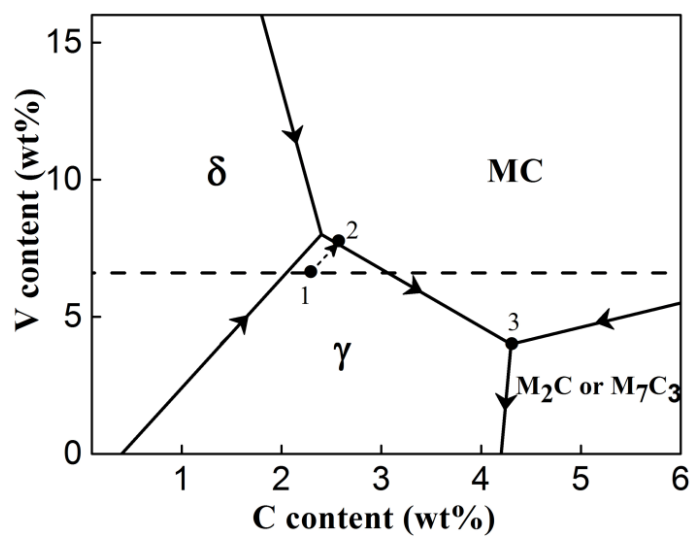

Fig. 16 Liquids surface diagram of $\mathrm{Fe}-5 \mathrm{Cr}-\mathrm{V}-\mathrm{C}$ alloy.
$\mathrm{L}+\mathrm{\gamma}$ reaction occurred, the main precipitated phase that appeared and grew in the liquid phase. When the temperature drops further to point 2, the primary phase passes through the bundle, and the binary eutectic reaction of $\mathrm{L} \rightarrow \mathrm{\gamma}+\mathrm{MC}$ occurs. Meanwhile, the two phases will be precipitated out, and the MC carbides nucleate only between the initial $\gamma$ and the liquid. The concentrations of $C$ and $\mathrm{V}$ in the liquid phase increased, and the solidification moved towards the direction of high carbon and high vanadium. With a decrease in temperature, the ternary eutectic reaction $\mathrm{L} \rightarrow+$ $\mathrm{MC}+\mathrm{M}_{7} \mathrm{C}_{3}$ occurred at point 3 .

In this test, the carbon content of the cast composite layer is $2.2 \mathrm{wt} \%$ and the $\mathrm{V}$ content is $6.6 \mathrm{wt} \%$, and its formation includes two processes: melting and solidification. The powder used to form the casting infiltration layer was melted and solidified at the pouring temperature of the molten steel. During solidification, gamma is first precipitated from the liquid phase, and when it reaches the eutectic point, a eutectic reaction occurs to generate $\gamma$ and the eutectic carbide VC (Figs. 7(a) and 7(b)). Subsequently, with a further reduction in temperature, secondary carbides precipitate in the matrix. This is owing to the solid phase transformation in the solidification process caused by casting infiltration, which led to the precipitation of some secondary phases. In addition, because the formation process of the casting composite layer involves the process of melting and solidification simultaneously, the dissolution process of some special elements is also included in the melting process, and the secondary phase precipitation is greatly increased compared with that of ordinary high-vanadium high-speed steel. The subsequent solidification process is similar to that of general high-vanadium high-speed steel.

It was concluded that the $\gamma$ phase and VC were mainly formed during solidification. The austenite grows into reverse and different bands of carbides, together with vanadium carbide. In addition, there are different bands of carbides and fast compounds in the matrix of high-toughness medium-carbon steel. This phenomenon can form the binding effect of the high-hard phase, and finally, the composite 
layer material with excellent wear resistance can be cast.

\subsection{Wear resistance of cast composite layer}

The main microstructures of the high-vanadium alloy cast composite layer are martensite, carbides $\mathrm{MC}, \mathrm{M}_{7} \mathrm{C}_{3}$, and retained austenite, which belong to martensite steel. After heat treatment, the Rockwell hardness was $63 \mathrm{HRC}$ and the microhardness reached 1,147.6 HV. Compared with the high-chromium cast iron BTMCr20, the hardness was higher; thus, the wear resistance was relatively good.

It can be seen from the above results that, after abrasive wear, the furrow formed on the surface of the high-vanadium alloy casting composite layer is wider and shallower than that of the high-chromium cast iron BTMCr20, with less wear. The carbides under the worn surface did not crack or break off. The main reason is that the eutectic carbides in the cast composite layer are smaller, secondary phase nano-reinforcing particles are formed, the hardness is higher, and the grooves formed are wider and shallower. Therefore, the sample exhibited good casting wear resistance.

After impact wear, serious pits and cutting grooves were formed on the surface of the high-chromium cast iron, and the wear loss was 1.26 times that of the cast composite layer of the high-vanadium alloy. Therefore, the high-chromium cast iron BTMCr20 has a poor impact wear resistance. This is because the rod carbides of the high-chromium cast iron BTMCr20 are not closely connected, and the hardness and number of carbides are not as high as those of vanadium carbides. The abrasive wear resistance of the cast composite layer of the high-vanadium alloy is 1.6 times higher than that of the high-chromium cast iron, and approximately three times higher than that of the matrix material.

\section{Conclusions}

In this study, the solidification structure and properties of high-vanadium and high-wear-resistance alloy casting composite layer castings were studied using a theoretical method of thermal analysis kinetics. The following conclusions were drawn:
Based on the solidification phase diagram, austenite was first precipitated in the casting composite layer during the solidification process; subsequently, a eutectic reaction was performed to generate $\gamma$ and $\mathrm{VC}$, and then a large amount of secondary phase nanoparticle carbide was precipitated from the austenite, most of which was VC.

Based on the SEM diagram, eutectic VC was uniformly distributed at the grain boundary, the secondary phase was mainly dispersed in the matrix, the white nanoparticles in the matrix increased significantly after heat treatment, and VC particles also became very small.

The casting vanadium alloyed layer has high hardness and strength, which is much better than the BTMCr20 of high-chromium cast iron, with excellent wear resistance.

The wear resistance of the cast composite layer was relatively good, the wear resistance of abrasive wear was approximately 1.6 times that of BTMCr20, and the impact abrasive wear was approximately 1.26 times. In addition, the excellent wear resistance of the cast composite layer was observed in the wear morphology.

\section{Acknowledgements}

The authors greatly acknowledge the National Natural Science Foundation of China (No. 51171060) and Program for Changjiang Scholars and Innovative Research Team in University (No. IRT1234).

Open Access This article is licensed under a Creative Commons Attribution 4.0 International License, which permits use, sharing, adaptation, distribution and reproduction in any medium or format, as long as you give appropriate credit to the original author(s) and the source, provide a link to the Creative Commons licence, and indicate if changes were made.

The images or other third party material in this article are included in the article's Creative Commons licence, unless indicated otherwise in a credit line to the material. If material is not included in the article's Creative Commons licence and your intended use is not permitted by statutory regulation or 
exceeds the permitted use, you will need to obtain permission directly from the copyright holder.

To view a copy of this licence, visit http://creativecommons.org/licenses/by/4.0/.

\section{References}

[1] Sun S Q, Wang Y X, Lu X J, Lu X, Mao C L, Zeng Z X. Achieving excellent tribological performance of a-C: WC film by controlling sub-nano-structure. Tribol Int 128: 65-74 (2018)

[2] Wei S Z, Xu L J. Review on research progress of steel and iron wear-resistant material. Acta Metall Sin 56(4): 523-538 (2020)

[3] Deng X T, Huang L, Wang Q, Fu T L, Wang Z D. Three-body abrasion wear resistance of TiC-reinforced low-alloy abrasion-resistant martensitic steel under dry and wet sand conditions, Wear 452-453: 203310 (2020)

[4] Xu L J, Wei S Z, Xiao F N, Zhou H, Zhang G S, Li J W. Effects of carbides on abrasive wear properties and failure behaviours of high speed steels with different alloy element content. Wear B 376-377: 968-974 (2017)

[5] Holmberg K, Erdemir A. Influence of tribology on global energy consumption, costs and emissions. Friction 5(3): 263-284 (2017)

[6] Xu L J, Fan X M, Wei S Z, Liu D D, Zhou H, Zhang G S, Zhou Y C. Microstructure and wear properties of highspeed steel with high molybdenum content under rolling-sliding wear. Tribol Int 116: 39-46 (2017)

[7] Chong X Y, Jiang Y H, Zhou R, Feng J. Electronic structures mechanical and thermal properties of $\mathrm{V}-\mathrm{C}$ binary compounds. RSC Adv 4(85): 44959-44971 (2014)

[8] Xu L J, Xing J D, Wei S Z, Zhang Y Z, Long R. Study on relative wear resistance and wear stability of high-speed steel with high vanadium content. Wear 262(3-4): 253-261 (2007)

[9] Mendas M, Stéphane B. Comparative study of abrasion via microindentation and microscratch tests of reinforced and unreinforced lamellar cast iron. Friction 7: 457-465 (2019)

[10] Marques F P, Scandian C, Bozzi A C, Fukumasu N K, Tschiptschin A P, Bozzi A C. Formation of a nanocrystalline recrystallized layer during microabrasive wear of a cobalt-chromium based alloy (Co-30Cr-19Fe). Tribol Int 116: 105-112 (2017)

[11] Xu L J, Wei S Z, Han M R, Long R. Effect of Carbides on Wear Characterization of High-Alloy Steels under High-Stress Rolling-Sliding Condition. Tribol T 57: 631-636 (2014)

[12] Xu L J, Wei S Z, Xing J D, Long R. Effects of carbon content and sliding ratio on wear behavior of high- vanadium high-speed steel (HVHSS) under high-stress rolling sliding contact. Tribol Int 70: 34-41 (2014)

[13] Zhang D W, Lei T C, Li F J. Laser cladding of stainless steel with $\mathrm{Ni}-\mathrm{Cr} 3 \mathrm{C} 2$ for improved wear performance. Wear 250(1-12): 1372-1376 (2001)

[14] Nurminen J, Näkki J, Vuoristo P. Microstructure and properties of hard and wear resistant MMC coatings deposited by laser cladding. Int $J$ Ref Meter \& H Mater 27(2): 472-478 (2009)

[15] Ignacio T, Cobley A J, Yi Z. Tribological performance of novel nickel-based composite coatings with lubricant particles. Friction 7: 169-180 (2019)

[16] Yun E, Lee S. Correlation of microstructure with hardness and wear resistance in $\mathrm{Cr} 3 \mathrm{C} 2 /$ stainless steel surface composites fabricated by high-energy electron beam irradiation. Mat Sci Eng A 405(1-2): 163-172 (2005)

[17] Chen S Y, Nambiar S, Li Z, Osei E, Darko J, Zheng W P, Sun Z D, Liu P, Yeow J T W. Bismuth oxide-based nanocomposite for high-energy electron radiation shielding. J Mater Sci 54(4): 3023-3034 (2019)

[18] Liu X B, Gu Y J. Plasma jet clad $\gamma / \mathrm{Cr}_{7} \mathrm{C}_{3}$ composite coating on steel. Mater Let 60(5): 577-580 (2006)

[19] Geng Z, Hou S H, Shi G L, Duan D L, Li S. Tribological behaviour at various temperatures of WC-Co coatings prepared using different thermal spraying techniques. Tribol Int 104: 36-44 (2016)

[20] Feng Z Q, Tang M Q, Liu Y Q, Yan Z W, Li G, Zhang R Z. In situ synthesis of TiC-TiN-reinforced Fe-base plasma cladding coatings. Surface Eng 34(4): 1-7 (2017)

[21] Jin G, Li Y, Cui H W, Cui X F, Cai Z B. Microstructure and Tribological Properties of In Situ Synthesized TiN Reinforced Ni/Ti Alloy Clad Layer Prepared by Plasma Cladding Technique. J Mater Eng Perform 25(6): 2412-2419 (2016)

[22] Zheng C, Liu Y H, Qin J, Chen C, Ji R J. Wear behavior of HVOF sprayed WC coating under water-in-oil fracturing fluid condition. Tribol Int 115: 28-34 (2017)

[23] Sawant M S, Jain N K. Investigations on wear characteristics of Stellite coating by micro-plasma transferred arc powder deposition process. Wear 378-379: 155-64 (2017)

[24] Zhang Z Z, Yang M M, Yuan J Y, Guo F, Men X H. Friction and wear behaviors of MoS2-multiwalledcarbonnanotube hybrid reinforced polyurethane composite coating. Friction 7(4): 316-326 (2019)

[25] Raghunath C, Bhat M S, Rohatgi P K. In situ technique for synthesizing Fe-TiC composites. Scripta Metall Mater 32(4): 577-582 (1995)

[26] Ballmes H, Klassen A, Rottmair C A, Singer R. Carbon long fiber reinforced aluminum matrix compositesParameter studies and numerical simulations of the infiltration process. Adva Eng Mater 12(7): 577-583 (2010) 
[27] Sube T, Kommer M, Fenker M, Hader B, Albrecht J. Reduced friction on gamma-Mo2N coatings deposited by high power impulse magnetron sputtering on microstructured surfaces. Tribol Int 106: 41-45 (2017)

[28] Jung C K, Jang J H, Han K S. Numerical Simulation of Infiltration and Solidification Processes for Squeeze Cast Al Composites with Parametric Study. Metall Mater Trans A 39(11): 2736-2748 (2008)

[29] Ren Y Y, Zhang G S, Wei S Z, Li J W. Influence of thermite reaction on the microstructures and properties of cast-infiltration composite layer. Adv Mater Res 602-604(5): 18-22 (2012)

[30] Li X, Gao T F, Jiang C H, Huang R Z. Surface alloying of $\mathrm{Au}$ atoms on a $\mathrm{Ni}(110)$ surface: A theoretical study. IOP Conference Series Mater Sci Eng 275(1): 24-26 (2017)

[31] Xu B, Yang J X, Feng C M. Microstructure and wear resistance of WC/high chromium cast iron composite layers. Mech Engineering Mater 23(4): 43-45 (1999)

[32] Uskov I V. Improving the wear resistance of steel castings by strengthening the surface with silicon-

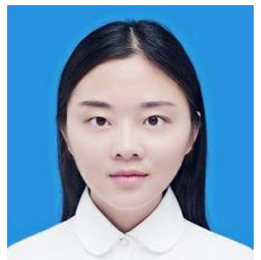

Fangfang WANG. She graduated from Henan University of Science and Technology with a bachelor's degree in material forming and control engineering in 2018. Then, she studied for a master's degree at the National Joint Engineering Research Center for Wear Control

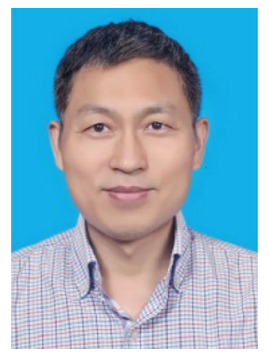

Liujie XU. He received his M.S. degree from Henan University of Science and Technology in 2004, and got his Ph.D. degree from Xi'an Jiaotong University in 2007, and then joined the faculty of Henan University of Science and Technology. He is a distinguished professor in colleges and universities of Henan Province. He is a national candidate for the "Millions carbide and chromium-car-bide powders. Sov J Fri Wear (2): 8 (1989)

[33] Ye F X, Hojamberdiev M, Xu Y H, Zhong L S, Zhao N N, Li Y P. Microstructure, microhardness and wear resistance of $\mathrm{VCp} / \mathrm{Fe}$ surface composites fabricated in situ. Appl Surface Sci 280(8): 297-303 (2013)

[34] Cao H T, Dong X P, Li W F, Pan Z, Wu X W, Huang Q W. Study on the microstructure and performance of ductile iron by PTA alloying high vanadium high-speed steel coating. Foundry 63(7): 637-641 (2014)

[35] Yang T L, Chen Y, Li X B. Microanalysis of vanadium chromium casting infiltration layer on cast steel surface and research on dry sliding wear performance. Cast 57(1): 15-19 (2008)

[36] Ray A K, Goswami B, Raj A, Singh MP. Studies on pyrometallurgy of vanadium bearing iron, steel and slag. J Metall Mater Sci 55(2): 99-111 (2013)

[37] Chang K K, Yong C K, Park J I, Sunghak L, Nack J K, Jung S Y. Effects of alloying elements on microstructure, hardness, and fracture toughness of centrifugally cast high-speed steel rolls. Metall Mater Trans A 36(1): 87-97 (2005)

and Forming of Metal Materials at Henan University of Science and Technology. She recently received a master's degree in materials science and engineering from Henan University of Science and Technology. Her research interests focus on the wear resistance, corrosion resistance and corrosion resistance of metallic wear-resistant materials.

of Talents Project" and an expert on Special Government Allowances of the State Council. He was awarded the National Science and Technology Progress Award of China (2013). Prof. Xu has been engaged in the research of new wear-resistant materials, the basic theory of materials wear, and the micro behavior of wear. He has published 152 papers and been invited as a keynote speaker for 8 times on the international conferences. 


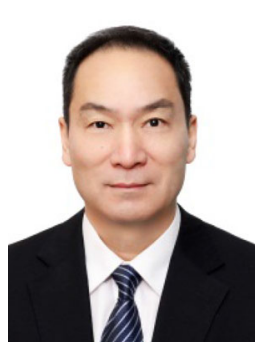

Shizhong WEI. He received his doctoral degree from Xi'an Jiaotong University in 2005. He is a state council expert for special allowance, a national candidate for the "Millions of Talent Projects", an expert of middle-aged and young with state outstanding contributions, a winner of the Ho Leung Ho Lee Foundation Award. He won the National Science and Technology Progress Award of China (2013, 2016), the first prize of China Machinery Industry Science and Technology Progress Award, the first prize of China Nonferrous Metals Industry Science and Technology Progress Award, and the first prize of Henan Province Science and Technology Progress Award. He is also the special chief expert for "the 13th Five-Year Plan" national key research and development program, the leader of "Program for Changjiang Scholars and Innovative Research Team in University" innovation team and the winner of State Industry, Science and Research Cooperation Innovation Award. Prof. Shizhong Wei has long-term been engaged in the research of "metallurgical molding process control technology". He has published 356 papers, been granted 65 patents for inventions, and published 5 monographs (till Jan. 1 2021). He has been invited as a keynote or plenary speaker for 21 times on the international conferences. 